\title{
Nine-Lump Kinetic Study of Catalytic Pyrolysis of Gas Oils Derived from Canadian Synthetic Crude Oil
}

\author{
Rui Zhang, Li Li, Zhichang Liu, and Xianghai Meng \\ State Key Laboratory of Heavy Oil Processing, China University of Petroleum, Beijing 102249, China \\ Correspondence should be addressed to Xianghai Meng; mengxh@cup.edu.cn
}

Received 20 December 2015; Revised 21 February 2016; Accepted 10 March 2016

Academic Editor: Dmitry Murzin

Copyright ( 2016 Rui Zhang et al. This is an open access article distributed under the Creative Commons Attribution License, which permits unrestricted use, distribution, and reproduction in any medium, provided the original work is properly cited.

\begin{abstract}
Catalytic pyrolysis of gas oils derived from Canadian synthetic crude oil on a kind of zeolite catalyst was conducted in a confined fluidized bed reactor for the production of light olefins. The overall reactants and products were classified into nine species, and a nine-lump kinetic model was proposed to describe the reactions based on appropriate assumptions. This kinetic model had 24 rate constants and a catalyst deactivation constant. The kinetic constants at $620^{\circ} \mathrm{C}, 640^{\circ} \mathrm{C}, 660^{\circ} \mathrm{C}$, and $680^{\circ} \mathrm{C}$ were estimated by means of nonlinear least-square regression method. Preexponential factors and apparent activation energies were then calculated according to the Arrhenius equation. The apparent activation energies of the three feed lumps were lower than those of the intermediate product lumps. The nine-lump kinetic model showed good calculation precision and the calculated yields were close to the experimental ones.
\end{abstract}

\section{Introduction}

Traditional catalytic cracking is an important process in refineries, aiming to produce gasoline and diesel. The target products will be light olefins (ethene, propene, and butene) if catalytic cracking is conducted at higher reaction temperature and larger catalyst to oil weight ratio, and the process is also called catalytic pyrolysis. Catalytic pyrolysis is a promising approach for producing light olefins. Having higher light olefin yields, lower energy consumption, and wider feed scope are a number of advantages of this process over conventional steam cracking. The catalytic pyrolysis feeds include butane $[1,2]$ or heavier alkanes $[3,4]$, butene $[5$, 6] or heavier olefins [7-9], $C_{5}$ raffinate [10], natural gasoline $[11]$, naphtha $[12,13]$, fluid catalytic cracking naphtha $[14,15]$, coker naphtha [15], gas oil $[16,17]$, heavy oil $[18,19]$, waste tire [20], plastic mixture [21], and bio-oil or biomass [22, 23].

Catalytic pyrolysis involves a series of complicated reactions, such as large molecules cracking, light olefins dimerization, carbonium ions isomerization, aromatization, and hydrogen transfer $[18,24]$. The kinetic study is important in understanding reactions, designing and simulating the reactor, predicting the reaction performance, and optimizing operating conditions.

The complex mixtures of catalytic pyrolysis can be described by lumping the large number of chemical compounds into groups of pseudo components according to the boiling points and molecular characteristics of the chemical compounds. Several lumping kinetic models are available for the catalytic pyrolysis of propane [25], $C_{4}$ hydrocarbons $[26,27]$, naphtha [28], gas oils $[16,29]$, and heavy oils [3032]. These studies can be used as references in the kinetic study of the catalytic pyrolysis of gas oils. One aim of lumping kinetic models is to select and optimize cracking feeds, which requires more than one feed lump in the model. However, most of the published lumping models contain only one feed lump. Nonaromatic and aromatic lumps are used to describe the cracking feeds in an eight-lump kinetic model for the catalytic pyrolysis of heavy oils [32]. Both the paraffinic and naphthenic groups belong to the nonaromatic lump, but their reaction performance is different.

Synthetic crude oil (SCO) derived from oils and bitumen is an important and abundant petroleum resource. China University of Petroleum has developed a suitable cracking 
TABLE 1: Feed properties.

\begin{tabular}{|c|c|c|c|c|c|}
\hline Feed & $\mathrm{HGO}$ & LGO & HAGO & HHVGO & HVGO \\
\hline Density $\left(20^{\circ} \mathrm{C}\right), \mathrm{g} / \mathrm{cm}^{3}$ & 0.9294 & 0.8782 & 0.8624 & 0.9136 & 0.9586 \\
\hline Carbon residue, wt $\%$ & 0.14 & 0.008 & 0.004 & 0.007 & 0.024 \\
\hline Mean molecular weight, $\mathrm{g} / \mathrm{mol}$ & 308 & 230 & 260 & 295 & 340 \\
\hline \multicolumn{6}{|l|}{ Elemental analysis } \\
\hline $\mathrm{C}, \mathrm{wt} \%$ & 87.68 & 87.41 & 86.07 & 87.79 & 85.22 \\
\hline $\mathrm{H}, \mathrm{wt} \%$ & 11.87 & 12.56 & 13.07 & 12 & 11.24 \\
\hline $\mathrm{S}, \mu \mathrm{g} / \mathrm{g}$ & 2700 & 271 & 3167 & 2806 & 30843 \\
\hline $\mathrm{N}, \mu \mathrm{g} / \mathrm{g}$ & 1800 & 21.8 & 174 & 975 & 1825 \\
\hline $\mathrm{H} / \mathrm{C}$ atomic ratio & 1.62 & 1.72 & 1.82 & 1.66 & 1.58 \\
\hline \multicolumn{6}{|l|}{ Distillation range } \\
\hline Initial boiling point (IBP), ${ }^{\circ} \mathrm{C}$ & 186 & 123 & 175 & 189 & 171 \\
\hline Final boiling point, ${ }^{\circ} \mathrm{C}$ & 583 & 474 & 422 & 546 & 576 \\
\hline $\mathrm{IBP} \sim 200^{\circ} \mathrm{C}, \mathrm{wt} \%$ & 0.8 & 8.4 & 1.0 & 1.1 & 0.6 \\
\hline $200 \sim 350^{\circ} \mathrm{C}, \mathrm{wt} \%$ & 25.6 & 70.9 & 65.7 & 42.9 & 13.5 \\
\hline $350 \sim 500^{\circ} \mathrm{C}, \mathrm{wt} \%$ & 65.1 & 20.7 & 33.3 & 53.4 & 79.1 \\
\hline$>500^{\circ} \mathrm{C}, \mathrm{wt} \%$ & 8.5 & 0 & 0 & 2.6 & 6.8 \\
\hline \multicolumn{6}{|l|}{ Structural group analysis, wt $\%$} \\
\hline Aromatic carbon & 24.7 & 10.9 & 14.7 & 22.1 & 29.0 \\
\hline Naphthenic carbon & 30.8 & 45.1 & 25.5 & 35.2 & 47.0 \\
\hline Paraffinic carbon & 44.5 & 44.0 & 59.8 & 42.7 & 24.0 \\
\hline$K_{\mathrm{CP}}$ & 3.09 & 3.37 & 3.68 & 3.21 & 2.95 \\
\hline
\end{tabular}

catalyst for SCO gas oils [33] in order to enlarge the feed source of light olefins production and to explore new processing ways of SCO. This study aims to investigate the cracking performance of several gas oils derived from Canadian SCO and to develop a nine-lump kinetic model with three feed lumps for the catalytic pyrolysis of gas oils. This research will give positive information for the development of new catalytic pyrolysis process.

\section{Experiments}

2.1. Feeds and Catalyst. Five kinds of gas oils, namely, heavy gas oil (HGO), light gas oil (LGO), heavy atmospheric gas oil (HAGO), heavy vacuum gas oil (HVGO) derived from Canadian SCO, and hydrotreated HVGO (HHVGO), were used in this research. The main properties of these feeds are listed in Table 1.

A kind of zeolite catalyst developed by China University of Petroleum for catalytic pyrolysis [33] was used in this study. The active components of the zeolite catalyst include modified HZSM-5, beta zeolite, and Y-faujasite zeolite. The main properties of the catalyst are listed in Table 2.

2.2. Apparatus. The experiments were conducted in a confined fluidized bed reactor with a filter on the bed top to prevent catalysts from escaping. The apparatus diagram is shown in Figure 1. The apparatus consisted of five sections, namely, oil and steam input mechanisms, a reaction zone, a temperature control system, and a product separation and collection system.
TABLE 2: Catalyst properties.

\begin{tabular}{lc}
\hline Item & Value \\
\hline Microactivity index & 72 \\
Surface area, $\mathrm{m}^{2} / \mathrm{g}$ & 130 \\
Pore volume, $\mathrm{cm}^{3} / \mathrm{g}$ & 0.21 \\
Packing density, $\mathrm{g} / \mathrm{cm}^{3}$ & 0.88 \\
Particle size distribution, $\mathrm{wt} \%$ & \\
$0 \sim 20 \mu \mathrm{m}$ & 4.8 \\
$20 \sim 40 \mu \mathrm{m}$ & 17.2 \\
$40 \sim 80 \mu \mathrm{m}$ & 47.8 \\
$>80 \mu \mathrm{m}$ & 30.2 \\
\hline
\end{tabular}

Experiments were conducted in batches, and the catalyst for each experiment is fresh. In each experiment, $50 \mathrm{~g}$ of the catalyst was loaded into the reactor, with an effective volume of approximately $580 \mathrm{~cm}^{3}$. Distilled water was pumped into a furnace to generate steam, which was used to fluidize the catalyst. Feedstock was pumped and mixed with the steam. The mixture was heated to approximately $500^{\circ} \mathrm{C}$ in a preheater and then entered the reactor. Reactions occurred as the feed made contact with the fluidized catalyst. After the reaction, the oil gas was cooled and separated into liquid and gas samples by the product separation and collection system. The spent catalyst was drawn out of the reactor by a vacuum pump. The pyrolysis experiments were performed at reaction temperatures between $600^{\circ} \mathrm{C}$ and $700^{\circ} \mathrm{C}$. 
TABLE 3: Feed conversion and product yield of various feeds at $640^{\circ} \mathrm{C}$.

\begin{tabular}{|c|c|c|c|c|c|}
\hline Feed & $\mathrm{HGO}$ & LGO & HAGO & HHVGO & HVGO \\
\hline Feed conversion, wt $\%$ & 69.20 & 72.40 & 80.40 & 69.84 & 76.87 \\
\hline \multicolumn{6}{|l|}{ Product yield, wt $\%$} \\
\hline Dry gas & 18.25 & 21.74 & 23.03 & 17.91 & 21.30 \\
\hline LPG & 24.60 & 27.74 & 34.10 & 28.84 & 26.56 \\
\hline Gasoline & 20.31 & 19.86 & 18.08 & 17.90 & 17.53 \\
\hline Diesel & 21.23 & 24.82 & 16.46 & 22.77 & 15.76 \\
\hline Heavy oil & 9.58 & 2.78 & 3.15 & 7.39 & 7.37 \\
\hline Coke & 6.04 & 3.06 & 5.18 & 5.19 & 11.47 \\
\hline Ethene & 9.16 & 10.34 & 12.01 & 8.65 & 8.85 \\
\hline Propene & 15.35 & 16.89 & 20.84 & 17.21 & 15.83 \\
\hline Butene & 7.32 & 8.38 & 10.92 & 9.76 & 8.24 \\
\hline Total light olefins & 31.83 & 35.61 & 43.77 & 35.62 & 32.91 \\
\hline Selectivity of total light olefins, $\%$ & 46.00 & 49.19 & 54.45 & 51.00 & 42.82 \\
\hline
\end{tabular}

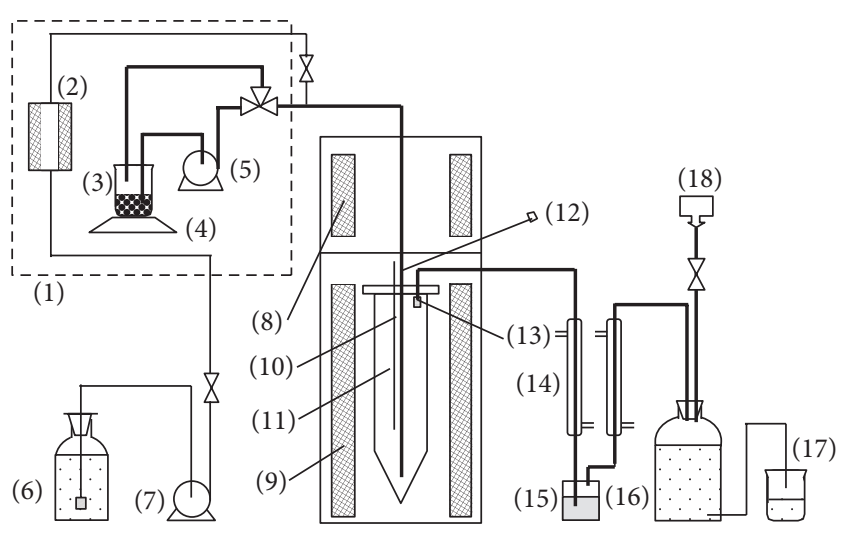

FIGURE 1: Diagram of the experimental setup ((1) constant temperature box; (2) steam furnace; (3) feedstock; (4) electronic balance; (5) oil pump; (6) water tank; (7) water pump; (8) preheater; (9) reactor furnace; (10) thermocouple; (11) reactor; (12) inlet and outlet of catalysts; (13) filter; (14) condenser; (15) collecting bottle for liquid products; (16) gas collection vessel; (17) beaker; (18) gas sample bag).

2.3. Analytical Methods. Pyrolysis products include gas, liquid, and coke. The gas sample was analyzed by a refinery gas analyzer to determine the volume percentage of the components. The analyzer was manufactured by Agilent Technologies Inc., which includes an Agilent 6890 gas chromatograph equipped with a hydrogen flame ionization detector and a thermal conductivity detector and a ChemStation software. Data were converted to mass percentages with the state equation of ideal gases. The liquid sample was analyzed with a simulated distillation gas chromatograph to obtain the mass percentage of gasoline $\left(C_{5}-200^{\circ} \mathrm{C}\right)$, diesel $\left(200-350^{\circ} \mathrm{C}\right)$, and heavy oil $\left(>350^{\circ} \mathrm{C}\right)$. The coke content of the spent catalyst was measured with a coke analyzer.

\section{Cracking Performance of Various Feeds}

The cracking performance of the five kinds of gas oils was investigated at $640^{\circ} \mathrm{C}$. Catalyst-to-oil weight ratio, weight hourly space velocity, and steam-to-oil weight ratio remained constant at $16.7,6.7 \mathrm{~h}^{-1}$, and 0.67 , respectively. Table 3 lists the feed conversion and product yields. In this study, feed conversion was the sum of the yields of dry gas, liquefied petroleum gas (LPG), gasoline, and coke.

$K_{\mathrm{CP}}$ (characterization factor) is proposed to characterize the cracking performance of various feeds and the cracking performance increases with increasing $K_{\mathrm{CP}}$ value [34]. The $K_{\mathrm{CP}}$ values of the feeds are listed in Table 1. HAGO showed the highest $K_{\mathrm{CP}}$ value and the best cracking performance among these feeds, the feed conversion reached $80.40 \mathrm{wt} \%$, the yield of total light olefins reached $43.77 \mathrm{wt} \%$, and the selectivity of total light olefins reached $54.45 \%$. The cracking performance of LGO and HHVGO ranked medium, the feed conversion was about $70 \mathrm{wt} \%$, the yield of total light olefins was about $35.6 \mathrm{wt} \%$, and the selectivity of total light olefins was around $50 \%$. The $K_{\mathrm{CP}}$ values of $\mathrm{HGO}$ and HVGO were low and the cracking performance of these feeds was not good, the yield of total light olefins was only about $32 \mathrm{wt} \%$, and the selectivity of total light olefins was around $44.4 \%$. The coke yield of HVGO reached $11.47 \%$, which was approximately twice that of the other feeds. This phenomenon may be caused by the large amount of aromatic and naphthenic carbon in HVGO.

\section{Development of Nine-Lump Kinetic Model}

4.1. Establishment of the Physical Model. The feed properties had a strong influence on product distribution. The feed was required to be divided into several lumps to widen the applicable scope of the model. The cracking performance of paraffins, naphthenes, and aromatics is quite different. The feed can be divided into three lumps, namely, paraffinic carbon (lump 1), naphthenic carbon (lump 2), and aromatic carbon (lump 3). The aromatic rings are stable and may thus have difficulty in undergoing ring-opening reactions under the present experimental conditions [35]. Therefore, aromatic carbon was not considered in the formation of gas products. However, the side chains of the aromatic rings could crack, lowering the boiling point of the aromatic component. Accordingly, 
aromatic carbons can form gasoline; however, the reaction differs from the cracking reactions of other feed lumps. Reactions among feed lumps are usually not considered; however, the reaction of naphthenic carbon to aromatic carbon was considered in this research because naphthenic rings could convert to aromatic rings by dehydrogenation reaction [36].

The targeted products of catalytic pyrolysis are light olefins, which are contained in dry gas and LPG. Hydrogen, methane, ethane, propane, and butane are byproducts. The formation mechanisms of these gas components are different; hydrogen, methane, and ethane are mainly formed through free radical mechanism, whereas ethene, propene, butene, propane, and butane are formed by both carbonium ion and free radical mechanisms [37]. Therefore, the gas components were divided into four lumps, namely, the combination of propene and butene (lump 5), the combination of propane and butane (lump 6), ethene (lump 7), and the combination of hydrogen, methane, and ethane (lump 8). The hydrogen transfer and dehydrogenation reactions between light olefins and light alkanes were neglected. No reaction was considered between lumps 5 and 6 . Similarly, no reaction was considered between lumps 7 and 8 .

Gasoline was considered a lump (lump 4) since it was the cracking intermediate product and its yield was high. Coke was also considered as one lump (lump 9) since coke yield was important to the thermal balance of catalytic pyrolysis.

Thus, a nine-lump kinetic model was established. The physical model (reaction network), which is shown in Figure 2 , contained 24 reactions. The nine-lump model was based on the previously reported seven-lump model [29]. The network of reactions among lumps 4, 5, 6, 7, 8, and 9 in the nine-lump model was similar to that of the seven-lump model.

4.2. Development of the Mathematical Model. In the physical model of the catalytic pyrolysis of gas oils, the reaction of lump $I$ forming lump $J$ can be expressed in the following mathematical model:

$$
I \stackrel{k_{i}}{\longrightarrow} v_{i j} J
$$

Several assumptions were made to simplify the mathematical model. The catalytic pyrolysis of gas oils is part of a gas-solid two phase catalytic reaction process, and the controlled steps are chemical reactions. The confined fluidized bed reactor can be considered an isothermal plug flow reactor. Radial dispersion in the reactor was negligible. The reaction order was assumed to be of the first order in this study because each lump did not consist of a complex mixture of different structure types of hydrocarbons and the boiling rage of each lump was not wide.

In the isothermal, gaseous phase and plug flow reactor, the reaction system can be described by the following continuity equation:

$$
\left(\frac{\partial \rho C_{i}}{\partial t}\right)_{x}+G_{V}\left(\frac{\partial C_{i}}{\partial x}\right)=r_{i}
$$

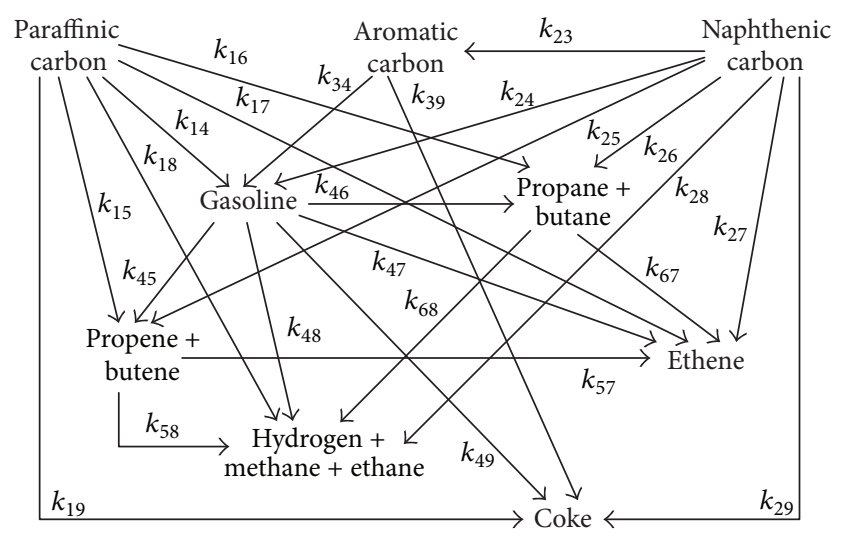

FIGURE 2: Reaction network of the nine-lump kinetic model.

The reaction rate $r_{i}$, which is proportional to the molar concentration of lump $I\left(\rho C_{i}\right)$ and the mass density of the catalyst to the gas volume $\left(\rho_{b} / \varepsilon\right)$ can also be expressed as follows:

$$
r_{i}=k_{i}^{\prime}\left(\rho C_{i}\right) \frac{\rho_{b}}{\varepsilon} .
$$

Rate constant $k_{i}^{\prime}$ is not a constant, and it decreased with catalyst time on stream as a result of catalyst deactivation. Equation (4) can be deduced from (2) and (3):

$$
\left(\frac{\partial \rho C_{i}}{\partial t}\right)_{x}+G_{V}\left(\frac{\partial C_{i}}{\partial x}\right)_{t}=-k_{i}^{\prime}\left(\rho C_{i}\right) \frac{\rho_{b}}{\varepsilon} .
$$

The residence time of oil gas was much shorter than that of the catalyst in the confined fluidized bed reactor, indicating that the changing speed of concentration over time was much lower than the changing speed of concentration with position. Therefore, (4) can be simplified to the following:

$$
G_{V} \frac{d C_{i}}{d x}=-k_{i}^{\prime}\left(\rho C_{i}\right) \frac{\rho_{b}}{\varepsilon} .
$$

The nondimensional length of the $x$ cross section in the bed $(X)$ can be expressed by $X=x / L$, where $x$ is the distance from the reactor entrance to the $x$ cross section in the bed, and $L$ is the total length of the bed. Equation (5) can be expressed as follows:

$$
\frac{G_{V}}{L} \frac{d C_{i}}{d X}=-k_{i}^{\prime}\left(\rho C_{i}\right) \frac{\rho_{b}}{\varepsilon} .
$$

Equation (7) can be obtained from the definition of $G_{V}$ and weight hourly space velocity $\left(S_{\mathrm{WH}}\right)$ :

$$
G_{V}=\frac{S_{\mathrm{WH}} \rho_{b} L}{\varepsilon} .
$$

Equation (8) can be deduced from (6) and (7):

$$
\frac{d C_{i}}{d X}=-\frac{1}{S_{\mathrm{WH}}} k_{i}^{\prime}\left(\rho C_{i}\right) .
$$


The catalyst activity decreases with catalyst time on stream. The catalyst deactivation function $(\phi)$ is often used to describe the influence of catalyst deactivation on reactions in kinetic studies of lumping models. The actual rate constant $k_{i}^{\prime}$ is equal to the product of the intrinsic rate constants $k_{i}$ and $\phi . k_{i}$ does not vary with time:

$$
k_{i}^{\prime}=k_{i} \phi
$$

The density of oil gas can be expressed as (10) with the assumption that the oil gas followed the state equation of ideal gases:

$$
\rho=\frac{P \bar{M}}{R T}
$$

Equation (11) can be deduced from (8) to (10):

$$
\frac{d C_{i}}{d X}=-\frac{1}{S_{\mathrm{WH}}} \cdot \frac{P \bar{M} \phi}{R T} \cdot k_{i} \cdot C_{i} .
$$

The mean molecular weight $(\bar{M})$ is not a constant, and it varied with $X . \bar{M}$ can be calculated using (12), where $i=0$ to consider the influence of steam on $\bar{M}$ :

$$
\bar{M}=\frac{\sum_{i=0}^{n} C_{i} M_{i}}{\sum_{i=0}^{n} C_{i}}=\frac{1}{\sum_{i=0}^{n} C_{i}} .
$$

According to the reaction network of the nine-lump kinetic model and (11), the mathematical equations of the nine lumps can be written as follows:

$$
\begin{aligned}
& \frac{d C_{1}}{d X}=-\frac{1}{S_{\mathrm{WH}}} \cdot \frac{P \bar{M}}{R T} \cdot\left(k_{14}+k_{15}+k_{16}+k_{17}+k_{18}+k_{19}\right) \cdot C_{1} \cdot \phi \text {, } \\
& \frac{d C_{2}}{d X}=-\frac{1}{S_{\mathrm{WH}}} \cdot \frac{P \bar{M}}{R T} \cdot\left(k_{23}+k_{24}+k_{25}+k_{26}+k_{27}+k_{28}+k_{29}\right) \cdot C_{2} \cdot \phi \text {, } \\
& \frac{d C_{3}}{d X}=\frac{1}{S_{\mathrm{WH}}} \cdot \frac{P \bar{M}}{R T} \cdot\left[v_{23} \cdot k_{23} \cdot C_{2}-\left(k_{34}+k_{39}\right) \cdot C_{3}\right] \cdot \phi \\
& \frac{d C_{4}}{d X}=\frac{1}{S_{\mathrm{WH}}} \cdot \frac{P \bar{M}}{R T} \cdot\left[\left(v_{14} \cdot k_{14} \cdot C_{1}+v_{24} \cdot k_{24} \cdot C_{2}+v_{34} \cdot k_{34} \cdot C_{3}\right)-\left(k_{45}+k_{46}+k_{47}+k_{48}+k_{49}\right) \cdot C_{4}\right] \cdot \phi \text {, } \\
& \frac{d C_{5}}{d X}=\frac{1}{S_{\mathrm{WH}}} \cdot \frac{P \bar{M}}{R T} \cdot\left[\left(v_{15} \cdot k_{15} \cdot C_{1}+v_{25} \cdot k_{25} \cdot C_{2}+v_{45} \cdot k_{45} \cdot C_{4}\right)-\left(k_{57}+k_{58}\right) \cdot C_{5}\right] \cdot \phi, \\
& \frac{d C_{6}}{d X}=\frac{1}{S_{\mathrm{WH}}} \cdot \frac{P \bar{M}}{R T} \cdot\left[\left(v_{16} \cdot k_{16} \cdot C_{1}+v_{26} \cdot k_{26} \cdot C_{2}+v_{46} \cdot k_{46} \cdot C_{4}\right)-\left(k_{67}+k_{68}\right) \cdot C_{6}\right] \cdot \phi, \\
& \frac{d C_{7}}{d X}=\frac{1}{S_{\mathrm{WH}}} \cdot \frac{P \bar{M}}{R T} \cdot\left[v_{17} \cdot k_{17} \cdot C_{1}+v_{27} \cdot k_{27} \cdot C_{2}+v_{47} \cdot k_{47} \cdot C_{4}+v_{57} \cdot k_{57} \cdot C_{5}+v_{67} \cdot k_{67} \cdot C_{6}\right] \cdot \phi \text {, } \\
& \frac{d C_{8}}{d X}=\frac{1}{S_{\mathrm{WH}}} \cdot \frac{P \bar{M}}{R T} \cdot\left[v_{18} \cdot k_{18} \cdot C_{1}+v_{28} \cdot k_{28} \cdot C_{2}+v_{48} \cdot k_{48} \cdot C_{4}+v_{58} \cdot k_{58} \cdot C_{5}+v_{68} \cdot k_{68} \cdot C_{6}\right] \cdot \phi \text {, } \\
& C_{9}=\frac{\left(1 /\left(1+R_{\mathrm{SO}}\right)-C_{1} M_{1}-C_{2} M_{2}-C_{3} M_{3}-C_{4} M_{4}-C_{5} M_{5}-C_{6} M_{6}-C_{7} M_{7}-C_{8} M_{8}\right)}{M_{9}} .
\end{aligned}
$$

The reasons for catalyst deactivation include coking, poisoning, and sintering, among which, coking was the most important. The catalyst deactivation function $(\phi)$ can be described by a function depending on catalyst time on stream, as shown in the following:

$$
\phi=\exp (-\alpha \cdot t)
$$

\section{Solutions of Model Parameters}

The nine-lump model contains 24 rate constants and a catalyst deactivation constant. The reaction performance of the gasoline lump was assumed to be similar to that of the seven-lump model [29] because the cracked gasoline showed a similar reaction performance [38]. The reaction performance of lumps 5 and 6 , as well as the catalyst deactivation performance, was also considered to be similar to those of the seven-lump model [29]. Therefore, the model parameters of $k_{45}, k_{46}, k_{47}, k_{48}, k_{49}, k_{57}, k_{58}, k_{67}, k_{68}$, and $\alpha$ were already known. The other 15 rate constants of the nine-lump model were estimated using the results obtained at the four reaction temperatures $\left(620^{\circ} \mathrm{C}, 640^{\circ} \mathrm{C}, 660^{\circ} \mathrm{C}\right.$, and $680^{\circ} \mathrm{C}$ ). These constants were estimated by solving the system of differential equations (Equations (13)). The system of differential equations was solved by a program compiled in MATLAB using Runge-Kutta method based on Taylor 
TABLE 4: Calculated kinetic constants.

\begin{tabular}{|c|c|c|c|c|c|}
\hline \multirow{2}{*}{ Reaction } & \multirow{2}{*}{ Unit } & \multicolumn{4}{|c|}{ Reaction temperature, ${ }^{\circ} \mathrm{C}$} \\
\hline & & 620 & 640 & 660 & 680 \\
\hline$k_{14}$ & {$\left[\mathrm{~g} / \mathrm{cm}^{3}\right]^{-1} \cdot \mathrm{h}^{-1}$} & 16881 & 18822 & 23535 & 27679 \\
\hline$k_{15}$ & {$\left[\mathrm{~g} / \mathrm{cm}^{3}\right]^{-1} \cdot \mathrm{h}^{-1}$} & 22011 & 26941 & 32355 & 36486 \\
\hline$k_{16}$ & {$\left[\mathrm{~g} / \mathrm{cm}^{3}\right]^{-1} \cdot \mathrm{h}^{-1}$} & 1817 & 1905 & 2089 & 2502 \\
\hline$k_{17}$ & {$\left[\mathrm{~g} / \mathrm{cm}^{3}\right]^{-1} \cdot \mathrm{h}^{-1}$} & 6124 & 8146 & 11205 & 14369 \\
\hline$k_{18}$ & {$\left[\mathrm{~g} / \mathrm{cm}^{3}\right]^{-1} \cdot \mathrm{h}^{-1}$} & 6982 & 9323 & 14155 & 20972 \\
\hline$k_{19}$ & {$\left[\mathrm{~g} / \mathrm{cm}^{3}\right]^{-1} \cdot \mathrm{h}^{-1}$} & 1808 & 2088 & 2616 & 3290 \\
\hline$k_{23}$ & {$\left[\mathrm{~g} / \mathrm{cm}^{3}\right]^{-1} \cdot \mathrm{h}^{-1}$} & 2405 & 2611 & 2995 & 3472 \\
\hline$k_{24}$ & {$\left[\mathrm{~g} / \mathrm{cm}^{3}\right]^{-1} \cdot \mathrm{h}^{-1}$} & 9072 & 10122 & 13280 & 15277 \\
\hline$k_{25}$ & {$\left[\mathrm{~g} / \mathrm{cm}^{3}\right]^{-1} \cdot \mathrm{h}^{-1}$} & 10914 & 13541 & 16410 & 18339 \\
\hline$k_{26}$ & {$\left[\mathrm{~g} / \mathrm{cm}^{3}\right]^{-1} \cdot \mathrm{h}^{-1}$} & 1090 & 1145 & 1266 & 1503 \\
\hline$k_{27}$ & {$\left[\mathrm{~g} / \mathrm{cm}^{3}\right]^{-1} \cdot \mathrm{h}^{-1}$} & 3086 & 4146 & 6399 & 7313 \\
\hline$k_{28}$ & {$\left[\mathrm{~g} / \mathrm{cm}^{3}\right]^{-1} \cdot \mathrm{h}^{-1}$} & 3981 & 5253 & 8375 & 12551 \\
\hline$k_{29}$ & {$\left[\mathrm{~g} / \mathrm{cm}^{3}\right]^{-1} \cdot \mathrm{h}^{-1}$} & 2468 & 2988 & 3973 & 5521 \\
\hline$k_{34}$ & {$\left[\mathrm{~g} / \mathrm{cm}^{3}\right]^{-1} \cdot \mathrm{h}^{-1}$} & 3258 & 4222 & 5422 & 6653 \\
\hline$k_{39}$ & {$\left[\mathrm{~g} / \mathrm{cm}^{3}\right]^{-1} \cdot \mathrm{h}^{-1}$} & 3675 & 5281 & 8287 & 11721 \\
\hline$k_{45}$ & {$\left[\mathrm{~g} / \mathrm{cm}^{3}\right]^{-1} \cdot \mathrm{h}^{-1}$} & 271 & 379 & 503 & 622 \\
\hline$k_{46}$ & {$\left[\mathrm{~g} / \mathrm{cm}^{3}\right]^{-1} \cdot \mathrm{h}^{-1}$} & 116 & 154 & 192 & 217 \\
\hline$k_{47}$ & {$\left[\mathrm{~g} / \mathrm{cm}^{3}\right]^{-1} \cdot \mathrm{h}^{-1}$} & 613 & 832 & 1214 & 1875 \\
\hline$k_{48}$ & {$\left[\mathrm{~g} / \mathrm{cm}^{3}\right]^{-1} \cdot \mathrm{h}^{-1}$} & 714 & 1015 & 1521 & 2661 \\
\hline$k_{49}$ & {$\left[\mathrm{~g} / \mathrm{cm}^{3}\right]^{-1} \cdot \mathrm{h}^{-1}$} & 1168 & 1622 & 2252 & 4483 \\
\hline$k_{57}$ & {$\left[\mathrm{~g} / \mathrm{cm}^{3}\right]^{-1} \cdot \mathrm{h}^{-1}$} & 540 & 790 & 1238 & 1984 \\
\hline$k_{58}$ & {$\left[\mathrm{~g} / \mathrm{cm}^{3}\right]^{-1} \cdot \mathrm{h}^{-1}$} & 326 & 535 & 942 & 1801 \\
\hline$k_{67}$ & {$\left[\mathrm{~g} / \mathrm{cm}^{3}\right]^{-1} \cdot \mathrm{h}^{-1}$} & 253 & 457 & 801 & 1388 \\
\hline$k_{68}$ & {$\left[\mathrm{~g} / \mathrm{cm}^{3}\right]^{-1} \cdot \mathrm{h}^{-1}$} & 213 & 436 & 813 & 1726 \\
\hline$\alpha$ & $h^{-1}$ & 30.8 & 37.5 & 44.3 & 51.2 \\
\hline
\end{tabular}

theorem. An objective function, which is shown in (15), was established, and Levenberg-Marquardt algorithm was used to accelerate the convergence of the objective function:

$$
\begin{aligned}
S(k)= & \sum\left[y_{\mathrm{obs}}-y_{\mathrm{cal}}(t, c(t, k))\right]^{T^{\prime}} \\
& *\left[y_{\mathrm{obs}}-y_{\mathrm{cal}}(t, c(t, k))\right] .
\end{aligned}
$$

Table 4 lists the kinetic constants at $620^{\circ} \mathrm{C}, 640^{\circ} \mathrm{C}, 660^{\circ} \mathrm{C}$, and $680^{\circ} \mathrm{C}$. The rate constants of the three feed lumps were significantly larger than those of the intermediate products, such as gasoline, the combination of propene and butene, and the combination of propane and butane. The rate constants of paraffinic carbon lump to gasoline and gas lumps were higher than those of the naphthenic carbon lump, indicating that paraffinic carbon was easier to crack than naphthenic carbon. The rate constant of aromatic carbon lump to coke was the highest among the three feed lumps, and the ratio of the rate constant of the aromatic carbon lump to coke to the rate constant of the aromatic carbon lump to gasoline increased with reaction temperature. This phenomenon showed that aromatic rings tended to form coke at high reaction temperatures. The rate constant of gasoline to coke was larger

\begin{tabular}{|c|c|c|c|}
\hline \multirow{2}{*}{ Reaction } & \multicolumn{2}{|c|}{ Preexponential factor } & \multirow{2}{*}{$\begin{array}{l}\text { Apparent activation energy, } \\
\mathrm{kJ} / \mathrm{mol}\end{array}$} \\
\hline & Unit & Value & \\
\hline$k_{14}$ & {$\left[\mathrm{~g} / \mathrm{cm}^{3}\right]^{-1} \cdot \mathrm{h}^{-1}$} & $4.43 \times 10^{7}$ & 59 \\
\hline$k_{15}$ & {$\left[\mathrm{~g} / \mathrm{cm}^{3}\right]^{-1} \cdot \mathrm{h}^{-1}$} & $6.64 \times 10^{7}$ & 59 \\
\hline$k_{16}$ & {$\left[\mathrm{~g} / \mathrm{cm}^{3}\right]^{-1} \cdot \mathrm{h}^{-1}$} & $3.04 \times 10^{5}$ & 38 \\
\hline$k_{17}$ & {$\left[\mathrm{~g} / \mathrm{cm}^{3}\right]^{-1} \cdot \mathrm{h}^{-1}$} & $4.67 \times 10^{9}$ & 101 \\
\hline$k_{18}$ & {$\left[\mathrm{~g} / \mathrm{cm}^{3}\right]^{-1} \cdot \mathrm{h}^{-1}$} & $1.80 \times 10^{11}$ & 130 \\
\hline$k_{19}$ & {$\left[\mathrm{~g} / \mathrm{cm}^{3}\right]^{-1} \cdot \mathrm{h}^{-1}$} & $2.50 \times 10^{7}$ & 71 \\
\hline$k_{23}$ & {$\left[\mathrm{~g} / \mathrm{cm}^{3}\right]^{-1} \cdot \mathrm{h}^{-1}$} & $8.37 \times 10^{5}$ & 44 \\
\hline$k_{24}$ & {$\left[\mathrm{~g} / \mathrm{cm}^{3}\right]^{-1} \cdot \mathrm{h}^{-1}$} & $3.62 \times 10^{7}$ & 62 \\
\hline$k_{25}$ & {$\left[\mathrm{~g} / \mathrm{cm}^{3}\right]^{-1} \cdot \mathrm{h}^{-1}$} & $4.06 \times 10^{7}$ & 61 \\
\hline$k_{26}$ & {$\left[\mathrm{~g} / \mathrm{cm}^{3}\right]^{-1} \cdot \mathrm{h}^{-1}$} & $1.86 \times 10^{5}$ & 38 \\
\hline$k_{27}$ & {$\left[\mathrm{~g} / \mathrm{cm}^{3}\right]^{-1} \cdot \mathrm{h}^{-1}$} & $2.68 \times 10^{9}$ & 101 \\
\hline$k_{28}$ & {$\left[\mathrm{~g} / \mathrm{cm}^{3}\right]^{-1} \cdot \mathrm{h}^{-1}$} & $3.47 \times 10^{11}$ & 136 \\
\hline$k_{29}$ & {$\left[\mathrm{~g} / \mathrm{cm}^{3}\right]^{-1} \cdot \mathrm{h}^{-1}$} & $9.23 \times 10^{8}$ & 96 \\
\hline$k_{34}$ & {$\left[\mathrm{~g} / \mathrm{cm}^{3}\right]^{-1} \cdot \mathrm{h}^{-1}$} & $2.72 \times 10^{8}$ & 84 \\
\hline$k_{39}$ & {$\left[\mathrm{~g} / \mathrm{cm}^{3}\right]^{-1} \cdot \mathrm{h}^{-1}$} & $3.71 \times 10^{11}$ & 137 \\
\hline$k_{45}$ & {$\left[\mathrm{~g} / \mathrm{cm}^{3}\right]^{-1} \cdot \mathrm{h}^{-1}$} & $1.43 \times 10^{8}$ & 98 \\
\hline$k_{46}$ & {$\left[\mathrm{~g} / \mathrm{cm}^{3}\right]^{-1} \cdot \mathrm{h}^{-1}$} & $2.35 \times 10^{6}$ & 73 \\
\hline$k_{47}$ & {$\left[\mathrm{~g} / \mathrm{cm}^{3}\right]^{-1} \cdot \mathrm{h}^{-1}$} & $3.30 \times 10^{10}$ & 133 \\
\hline$k_{48}$ & {$\left[\mathrm{~g} / \mathrm{cm}^{3}\right]^{-1} \cdot \mathrm{h}^{-1}$} & $9.07 \times 10^{11}$ & 156 \\
\hline$k_{49}$ & {$\left[\mathrm{~g} / \mathrm{cm}^{3}\right]^{-1} \cdot \mathrm{h}^{-1}$} & $2.47 \times 10^{12}$ & 160 \\
\hline$k_{57}$ & {$\left[\mathrm{~g} / \mathrm{cm}^{3}\right]^{-1} \cdot \mathrm{h}^{-1}$} & $5.30 \times 10^{11}$ & 154 \\
\hline$k_{58}$ & {$\left[\mathrm{~g} / \mathrm{cm}^{3}\right]^{-1} \cdot \mathrm{h}^{-1}$} & $2.13 \times 10^{14}$ & 202 \\
\hline$k_{67}$ & {$\left[\mathrm{~g} / \mathrm{cm}^{3}\right]^{-1} \cdot \mathrm{h}^{-1}$} & $1.41 \times 10^{14}$ & 201 \\
\hline$k_{68}$ & {$\left[\mathrm{~g} / \mathrm{cm}^{3}\right]^{-1} \cdot \mathrm{h}^{-1}$} & $5.95 \times 10^{16}$ & 247 \\
\hline$\alpha$ & $h^{-1}$ & $9.79 \times 10^{4}$ & 60 \\
\hline
\end{tabular}

TABLE 5: Apparent activation energies and preexponential factors.

than the rate constants of gasoline to other lumps because the intermediate product gasoline contained a large amount of aromatic rings [35], indicating that the cracking performance of gasoline was poor.

The preexponential factors and apparent activation energies (listed in Table 5) were then calculated using (16) (Arrhenius equation). The apparent activation energies to ethene and to the combination of hydrogen, methane, and ethane were significantly greater than the energies to other lumps. This phenomenon showed that the free radical mechanism played an important role in the formation of these light gas products. The apparent activation energies of the three feed lumps to gasoline, the combination of propene and butene, and the combination of propane and butane were low, suggesting that the carbonium ion mechanism played a significant role in the formation of these products. The apparent activation energy of the aromatic carbon lump to coke was significantly greater than the energies of the naphthenic and paraffinic carbon lumps, suggesting that thermal condensation played an important role in the formation of coke from aromatic rings:

$$
k=k_{0} \exp \left(-\frac{E}{R T}\right) .
$$


TABLE 6: Average relative error of lump yields at four temperatures, \%.

\begin{tabular}{lcccc}
\hline Reaction temperature, ${ }^{\circ} \mathrm{C}$ & 620 & 640 & 660 & 680 \\
Gasoline & 6.7 & 5.8 & 7.0 & 6.2 \\
Propene + butene & 4.4 & 4.6 & 5.2 & 4.1 \\
Propane + butane & 10.1 & 9.5 & 9.2 & 10.8 \\
Ethene & 4.5 & 5.7 & 5.5 & 6.1 \\
Hydrogen + methane + ethane & 5.2 & 6.2 & 4.6 & 5.3 \\
Coke & 4.6 & 5.9 & 4.5 & 5.4 \\
\hline
\end{tabular}

The apparent activation energies are reportedly between 210 and $290 \mathrm{~kJ} / \mathrm{mol}$ for hydrocarbon thermal cracking and between 42 and $125 \mathrm{~kJ} / \mathrm{mol}$ for catalytic cracking [39]. Most of the apparent activation energies forming gasoline (lump 4 ), the combination of propene and butene (lump 5), and the combination of propane and butane (lump 6) determined in this study are lower than $100 \mathrm{~kJ} / \mathrm{mol}$. Thus, catalytic cracking, with the help of the catalyst, plays an important role in gas oil catalytic pyrolysis. However, most of the apparent activation energies forming ethene (lump 7), the combination of hydrogen, methane, and ethane (lump 8), and coke (lump 9) determined in this study are between 100 and $250 \mathrm{~kJ} / \mathrm{mol}$, indicating that both catalytic cracking and thermal cracking play important roles.

\section{Model Test and Prediction}

6.1. Calculation Error. Table 6 shows the calculated average relative error of the product lump yields at four temperatures. The calculated average relative errors were gasoline $6.4 \%$, the combination of propene and butene $4.6 \%$, the combination of propane and butane $9.9 \%$, ethene $5.5 \%$, the combination of hydrogen, methane, and ethane 5.3\%, and coke 5.1\%. The calculated average relative error was approximately $6 \%$, indicating that the calculated yield was close to the experimental one. In addition, model parameters showed different sensitivities to calculated yields and parameter relative errors were below $15 \%$. The calculated average relative error of the combination of propane and butane was much larger than those of the other product lumps because the yield of the combination of propane and butane was quite low (approximately $2 \mathrm{wt} \%$ ). Figure 3 shows the comparison of the experimental yields (points) and the model-predicted yields (line) at $640^{\circ} \mathrm{C}$. The predicted yields were close to the experimental ones. These results show that the nine-lump kinetic model had accurate calculation and that the calculated results were reliable.

6.2. Variation in Product Yields with Reaction Temperature. The rate constants at different temperatures were calculated using Arrhenius equation. The variation in product yields was predicted with reaction temperatures ranging from $600^{\circ} \mathrm{C}$ to $700^{\circ} \mathrm{C}$ in HAGO catalytic pyrolysis. Catalyst-tooil weight ratio, weight hourly space velocity, and steam-tooil weight ratio remained constant at $16.7,6.7 \mathrm{~h}^{-1}$, and 0.67 , respectively.

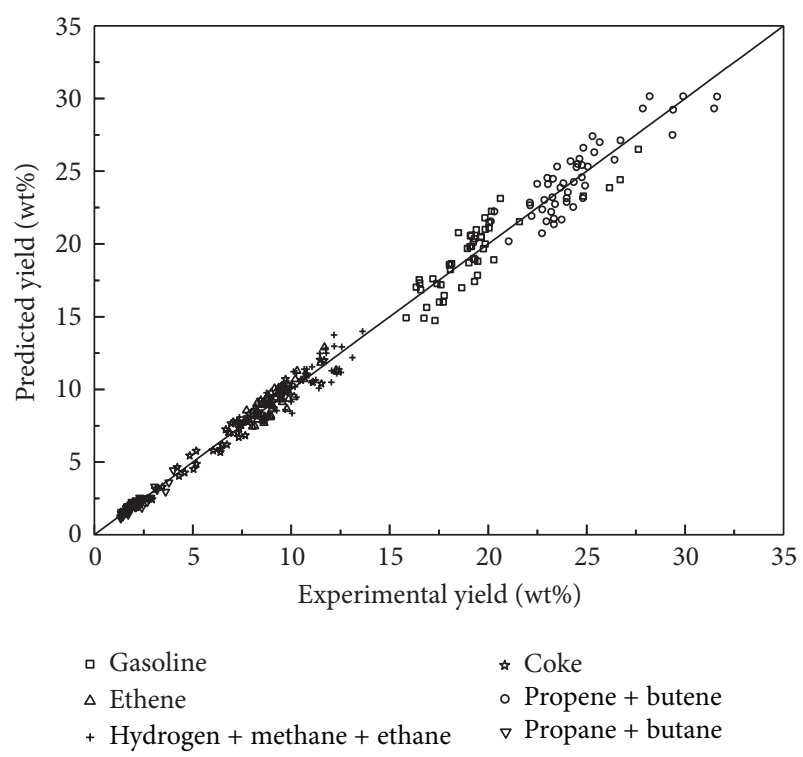

FIGURE 3: Comparison of the experimental yields (points) and the model-predicted yields (line) in HAGO catalytic pyrolysis at $640^{\circ} \mathrm{C}$.

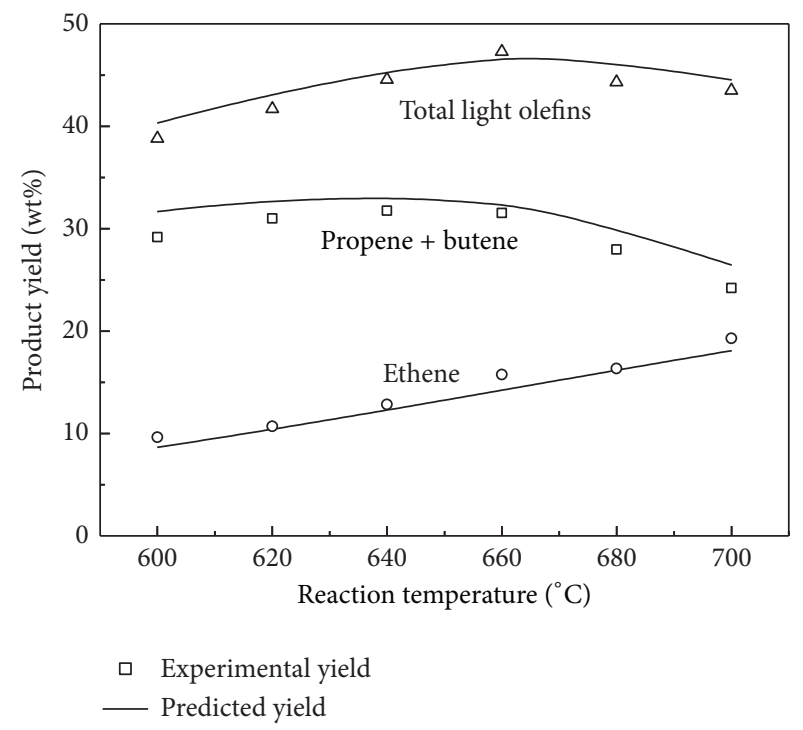

Figure 4: Predicted and experimental light olefin yields as a function of reaction temperature (catalytic pyrolysis of HAGO, catalystto-oil weight ratio of 16.7 , weight hourly space velocity of $4.87 \mathrm{~h}^{-1}$, and steam-to-oil weight ratio of 0.67 ).

Figures 4 and 5 illustrate the predicted yields of products (lines) and the experimental yields (points). The predicted yields were close to the experimental ones. The yields of ethene, the combination of hydrogen, methane, and ethane, and coke monotonously increased with increasing temperature, the yield of the combination of propane and butane decreased slightly, whereas the yields of the combination of propene and butene and gasoline reached maxima at approximately $640^{\circ} \mathrm{C}$. The total light olefin yield reached the maximum at approximately $660^{\circ} \mathrm{C}$. 


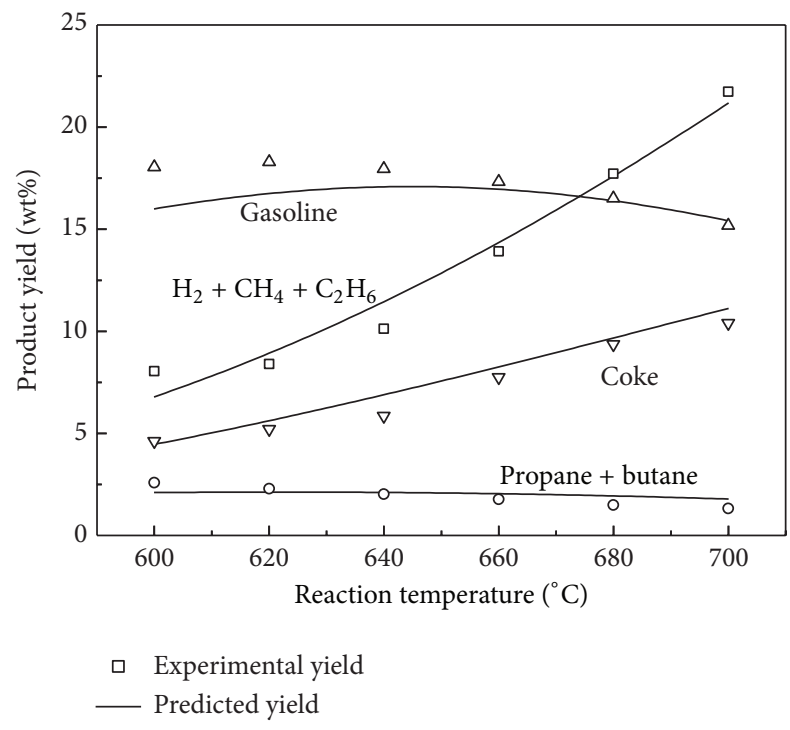

FIGURE 5: Predicted and experimental product lump yields as a function of reaction temperature (catalytic pyrolysis of HAGO, catalyst-to-oil weight ratio of 16.7 , weight hourly space velocity of $4.87 \mathrm{~h}^{-1}$, and steam-to-oil weight ratio of 0.67 ).

\section{Conclusions}

(1) The cracking performance of HAGO was good, that of LGO and HHVGO ranked medium, and that of HGO and HVGO was poor.

(2) The reactants and products of gas oil catalytic pyrolysis were classified into nine lumps, namely, paraffinic carbon, naphthenic carbon, aromatic carbon, gasoline, the combination of propene and butene, the combination of propane and butane, ethene, the combination of hydrogen, methane, and ethane, and coke. A nine-lump kinetic model was established to describe the reactions, and the kinetic model had 24 rate constants and a catalyst deactivation constant. The mathematical equations of the nine-lump model were deduced.

(3) The kinetic constants at $620^{\circ} \mathrm{C}, 640^{\circ} \mathrm{C}, 660^{\circ} \mathrm{C}$, and $680^{\circ} \mathrm{C}$ were estimated by means of nonlinear leastsquare regression method. Preexponential factors and apparent activation energies were then calculated using Arrhenius equation. The rate constants of the feed lumps were larger than those of the intermediate product lumps, and the apparent activation energies of the feed lumps were lower than those of the intermediate product lumps.

(4) The nine-lump kinetic model had accurate calculation, and the predicted yields agreed with the experimental ones.

\section{Nomenclature}

$\alpha$ : Catalyst deactivation constant

$\rho$ : Gas density, $\mathrm{g} / \mathrm{cm}^{3}$ $\rho_{b}: \quad$ Density of the catalyst in

the bed, $\mathrm{g} / \mathrm{cm}^{3}$

$\varepsilon: \quad$ Void fraction of the bed

$\phi$ : Catalyst deactivation function

$v_{i j}$ : Chemical measurement coefficient for the reaction of lump I to lump $J$

c: Concentration vector

cal: Calculated data

$C_{i}$ : Concentration of lump $I$ in the gas phase, $\mathrm{mol} / \mathrm{g}$

$E$ : Apparent activation energy, $\mathrm{kJ} / \mathrm{mol}$

$G_{V}$ : Mass velocity in the cross section of the reactor, $\mathrm{g} /\left(\mathrm{cm}^{2} \cdot \mathrm{h}\right)$

$I, J:$ Lump species $I$ and $J$

$k_{0}$ : Preexponential factors, $\left[\mathrm{g} / \mathrm{cm}^{3}\right]^{-1} \cdot \mathrm{h}^{-1}$

$k_{i}$ : Rate constant of lump $I$, $\left[\mathrm{g} / \mathrm{cm}^{3}\right]^{-1} \cdot \mathrm{h}^{-1}$

$L: \quad$ Total length of the bed, $\mathrm{cm}$

$\bar{M}$ : Average molecular weight of gaseous components, $\mathrm{g} / \mathrm{mol}$

$M_{i}$ : Average molecular weight of lump $I$ in gas phase, $\mathrm{g} / \mathrm{mol}$

obs: Experimental data

$P: \quad$ Reaction pressure, $\mathrm{Pa}$

$r_{i}$ : Reaction rate of lump $I$, $\mathrm{mol} /\left(\mathrm{cm}^{3} \cdot \mathrm{h}\right)$

$R: \quad$ Gas constant, $\mathrm{J} \cdot \mathrm{mol}^{-1} \cdot \mathrm{K}^{-1}$

$R_{\mathrm{SO}}$ : Steam-to-oil weight ratio

$S: \quad$ Objective function

$S_{\mathrm{WH}}$ : Total weight hourly space velocity, $\mathrm{h}^{-1}$

$t$ : Catalyst time on stream, $\mathrm{h}$

$T$ : $\quad$ Reaction temperature, $\mathrm{K}$

$T^{\prime}$ : $\quad$ Transpose of vector matrix

$x$ : Distance from the reactor entrance to the $x$ cross section in the bed, $\mathrm{cm}$

$X: \quad$ Nondimensional length of the $x$ cross section in the bed

$y$ : Observed variable.

\section{Competing Interests}

The authors declare that they have no competing interests.

\section{Acknowledgments}

Financial support was provided by the National Basic Research Program of China (973 Program no. 2012CB215001) and the Program for New Century Excellent Talents in the University of China (no. NCET-12-0970).

\section{References}

[1] J. Y. Lu, Z. Zhao, C. M. Xu, P. Zhang, and A. J. Duan, "FeHZSM5 molecular sieves-highly active catalysts for catalytic cracking of isobutane to produce ethylene and propylene," Catalysis Communications, vol. 7, no. 4, pp. 199-203, 2006. 
[2] G. Y. Jiang, L. Zhang, Z. Zhao et al., "Highly effective P-modified HZSM-5 catalyst for the cracking of $\mathrm{C}_{4}$ alkanes to produce light olefins," Applied Catalysis A: General, vol. 340, no. 2, pp. 176-182, 2008.

[3] K. K. Pant and D. Kunzru, "Catalytic pyrolysis of n-heptane on unpromoted and potassium promoted calcium aluminates," Chemical Engineering Journal, vol. 87, no. 2, pp. 219-225, 2002.

[4] J. S. Jung, J. W. Park, and G. Seo, "Catalytic cracking of n-octane over alkali-treated MFI zeolites," Applied Catalysis A: General, vol. 288, no. 1-2, pp. 149-157, 2005.

[5] N. H. Xue, L. Nie, D. M. Fang et al., "Synergistic effects of tungsten and phosphorus on catalytic cracking of butene to propene over HZSM-5," Applied Catalysis A: General, vol. 352, no. 1-2, pp. 87-94, 2009.

[6] X. X. Zhu, S. L. Liu, Y. Q. Song, S. J. Xie, and L. Y. Xu, "Catalytic cracking of 1-butene to propene and ethene on MCM-22 zeolite," Applied Catalysis A: General, vol. 290, no. 1-2, pp. 191-199, 2005.

[7] Z. Nawaz, X. Tang, and F. Wei, "Hexene catalytic cracking over $30 \%$ sapo-34 catalyst for propylene maximization: influence of reaction conditions and reaction pathway exploration," Brazilian Journal of Chemical Engineering, vol. 26, no. 4, pp. 705-712, 2009.

[8] Z. Nawaz, X. Tang, J. Zhu, F. Wei, and S. Naveed, "Catalytic cracking of 1-hexene to propylene using SAPO-34 catalysts with different bulk topologies," Chinese Journal of Catalysis, vol. 30, no. 10, pp. 1049-1057, 2009.

[9] R. Le Van Mao, A. Muntasar, H. T. Yan, and Q. Zhao, "Catalytic cracking of heavy olefins into propylene, ethylene and other light olefins," Catalysis Letters, vol. 130, no. 1-2, pp. 86-92, 2009.

[10] J. Lee, U. G. Hong, S. Hwang, M. H. Youn, and I. K. Song, "Catalytic cracking of $\mathrm{C}_{5}$ raffinate to light olefins over lanthanumcontaining phosphorous-modified porous ZSM-5: effect of lanthanum content," Fuel Processing Technology, vol. 109, pp. 189-195, 2013.

[11] M. J. B. Souza, F. A. N. Fernandes, A. M. G. Pedrosa, and A. S. Araujo, "Selective cracking of natural gasoline over HZSM-5 zeolite," Fuel Processing Technology, vol. 89, no. 9, pp. 819-827, 2008.

[12] S. M. Jeong, J. H. Chae, and W. H. Lee, "Study on the catalytic pyrolysis of naphtha over a $\mathrm{KVO}_{3} / \alpha-\mathrm{Al}_{2} \mathrm{O}_{3}$ catalyst for production of light olefins," Industrial \& Engineering Chemistry Research, vol. 40, no. 26, pp. 6081-6086, 2001.

[13] S. M. Jeong, J. H. Chae, J. H. Kang, S. H. Lee, and W. H. Lee, "Catalytic pyrolysis of naphtha on the $\mathrm{KVO}_{3}$-based catalyst," Catalysis Today, vol. 74, no. 3-4, pp. 257-264, 2002.

[14] G. Wang, C. M. Xu, and J. S. Gao, "Study of cracking FCC naphtha in a secondary riser of the FCC unit for maximum propylene production," Fuel Processing Technology, vol. 89, no. 9, pp. 864-873, 2008.

[15] W. K. Liu, X. H. Meng, X. Zhao, G. Wang, J. S. Gao, and C. M. $\mathrm{Xu}$, "Pyrolysis performances of catalytic cracking naphtha and coker naphtha on inert carriers and an active catalyst," Energy \& Fuels, vol. 23, no. 12, pp. 5760-5764, 2009.

[16] L. Li, G. Wang, X. H. Meng, C. M. Xu, and J. S. Gao, "Catalytic pyrolysis of gas oil derived from Canadian oil sands bitumen," Industrial \& Engineering Chemistry Research, vol. 47, no. 3, pp. 710-716, 2008.

[17] R. Bastiani, Y. L. Lam, C. A. Henriques, and V. T. Da Silva, "Application of ferrierite zeolite in high-olefin catalytic cracking," Fuel, vol. 107, pp. 680-687, 2013.
[18] X. H. Meng, C. M. Xu, J. S. Gao, and L. Li, "Studies on catalytic pyrolysis of heavy oils: reaction behaviors and mechanistic pathways," Applied Catalysis A: General, vol. 294, no. 2, pp. 168176, 2005.

[19] X. H. Meng, C. M. Xu, J. S. Gao, L. Li, and Z. C. Liu, "Catalytic and thermal pyrolysis of atmospheric residue," Energy \& Fuels, vol. 23, no. 1, pp. 65-69, 2009.

[20] N. A. Dũng, R. Klaewkla, S. Wongkasemjit, and S. Jitkarnka, "Light olefins and light oil production from catalytic pyrolysis of waste tire," Journal of Analytical and Applied Pyrolysis, vol. 86, no. 2, pp. 281-286, 2009.

[21] D. P. Serrano, J. Aguado, J. M. Escola, J. M. Rodríguez, L. Morselli, and R. Orsi, "Thermal and catalytic cracking of a LDPEEVA copolymer mixture," Journal of Analytical and Applied Pyrolysis, vol. 68-69, pp. 481-494, 2003.

[22] A. G. Gayubo, B. Valle, A. T. Aguayo, M. Olazar, and J. Bilbao, "Olefin production by catalytic transformation of crude biooil in a two-step process," Industrial \& Engineering Chemistry Research, vol. 49, no. 1, pp. 123-131, 2010.

[23] H. Y. Zhang, R. Xiao, B. S. Jin, G. Xiao, and R. Chen, "Biomass catalytic pyrolysis to produce olefins and aromatics with a physically mixed catalyst," Bioresource Technology, vol. 140, pp. 256-262, 2013.

[24] L. Li, J. S. Gao, C. M. Xu, and X. H. Meng, "Reaction behaviors and mechanisms of catalytic pyrolysis of C4 hydrocarbons," Chemical Engineering Journal, vol. 116, no. 3, pp. 155-161, 2006.

[25] X. Wang, H. Carabineiro, F. Lemos, M. A. N. D. A. Lemos, and F. Ramôa Ribeiro, "Propane conversion over a H-ZSM5 acid catalyst: part 1. Observed kinetics," Journal of Molecular Catalysis A: Chemical, vol. 216, no. 1, pp. 131-137, 2004.

[26] X. H. Meng, C. M. Xu, L. Li, and J. S. Gao, "Kinetic study of catalytic pyrolysis of $\mathrm{C} 4$ hydrocarbons on a modified ZSM-5 zeolite catalyst," Energy \& Fuels, vol. 24, no. 12, pp. 6233-6238, 2010.

[27] D. Mier, A. T. Aguayo, M. Gamero, A. G. Gayubo, and J. Bilbao, "Kinetic modeling of n-butane cracking on HZSM-5 zeolite catalyst," Industrial \& Engineering Chemistry Research, vol. 49, no. 18, pp. 8415-8423, 2010.

[28] M. Sedighi, K. Keyvanloo, and J. Towfighi, "Kinetic study of steam catalytic cracking of naphtha on a Fe/ZSM-5 catalyst," Fuel, vol. 109, pp. 432-438, 2013.

[29] X. H. Meng, C. M. Xu, L. Li, and J. S. Gao, "Kinetics of catalytic pyrolysis of heavy gas oil derived from Canadian synthetic crude oil," Energy \& Fuels, vol. 25, no. 8, pp. 3400-3407, 2011.

[30] X. H. Meng, C. M. Xu, L. Li, and J. S. Gao, "Studies on the kinetics of heavy oil catalytic pyrolysis," Industrial \& Engineering Chemistry Research, vol. 42, no. 24, pp. 6012-6019, 2003.

[31] Y. B. Liu, X. B. Chen, H. Zhao, and C. H. Yang, "Establishment of kinetic model for catalytic pyrolysis of daqing atmospheric residue," Chinese Journal of Chemical Engineering, vol. 17, no. 1, pp. 78-82, 2009.

[32] X. H. Meng, C. M. Xu, J. S. Gao, and L. Li, "Catalytic pyrolysis of heavy oils: 8-lump kinetic model," Applied Catalysis A: General, vol. 301, no. 1, pp. 32-38, 2006.

[33] B. J. Shen, J. S. Gao, C. M. Xu, L. Zhao, X. F. Li, and P. Wu, "Catalyst composition for treating heavy feedstocks," US 20070209969 , September 2007.

[34] X. H. Meng, C. M. Xu, L. Li, and J. S. Gao, "Cracking performance and feed characterization study of catalytic pyrolysis for light olefin production," Energy \& Fuels, vol. 25, no. 4, pp. 13571363, 2011. 
[35] Z. C. Liu, X. H. Meng, C. M. Xu, and J. S. Gao, "Secondary cracking of gasoline and diesel from heavy oil catalytic pyrolysis," Chinese Journal of Chemical Engineering, vol. 15, no. 3, pp. 309-314, 2007.

[36] H. Zhu, X. B. Liu, Q. J. Ge, W. Z. Li, and H. Y. Xu, "Production of lower alkenes and light fuels by gas phase oxidative cracking of heavy hydrocarbons," Fuel Processing Technology, vol. 87, no. 7, pp. 649-657, 2006.

[37] L. Li, X. H. Meng, C. M. Xu, and J. S. Gao, "Reaction behavior and product formation mechanism of catalytic and thermal pyrolysis of gas oils derived from Canadian synthetic crude oil," Journal of Fuel Chemistry and Technology, vol. 38, no. 2, pp. 183$189,2010$.

[38] X. H. Meng, C. M. Xu, L. Li, and J. S. Gao, "Cracking performance of gasoline and diesel fractions from catalytic pyrolysis of heavy gas oil derived from Canadian synthetic crude oil," Energy \& Fuels, vol. 25, no. 8, pp. 3382-3388, 2011.

[39] C. M. Xu and C. H. Yang, Petroleum Refining Engineering, China Petroleum Industry Press, Beijing, China, 4th edition, 2009. 


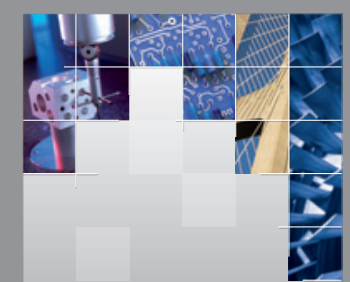

\section{Enfincering}
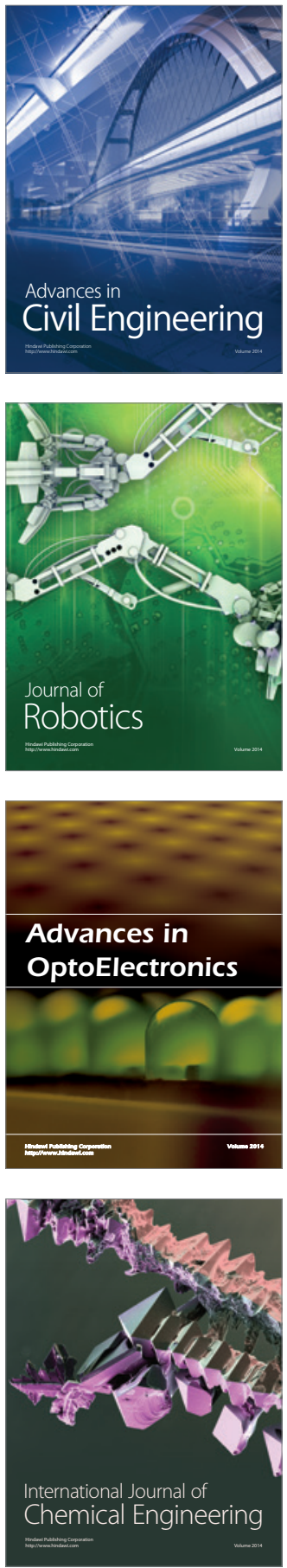

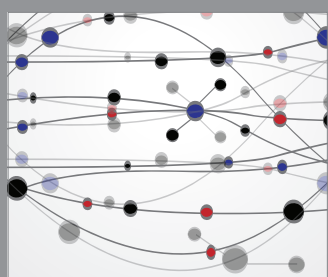

The Scientific World Journal

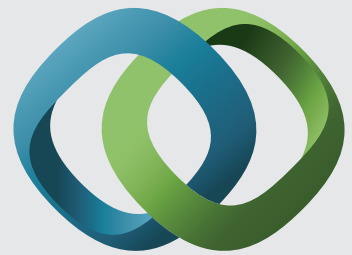

\section{Hindawi}

Submit your manuscripts at

http://www.hindawi.com
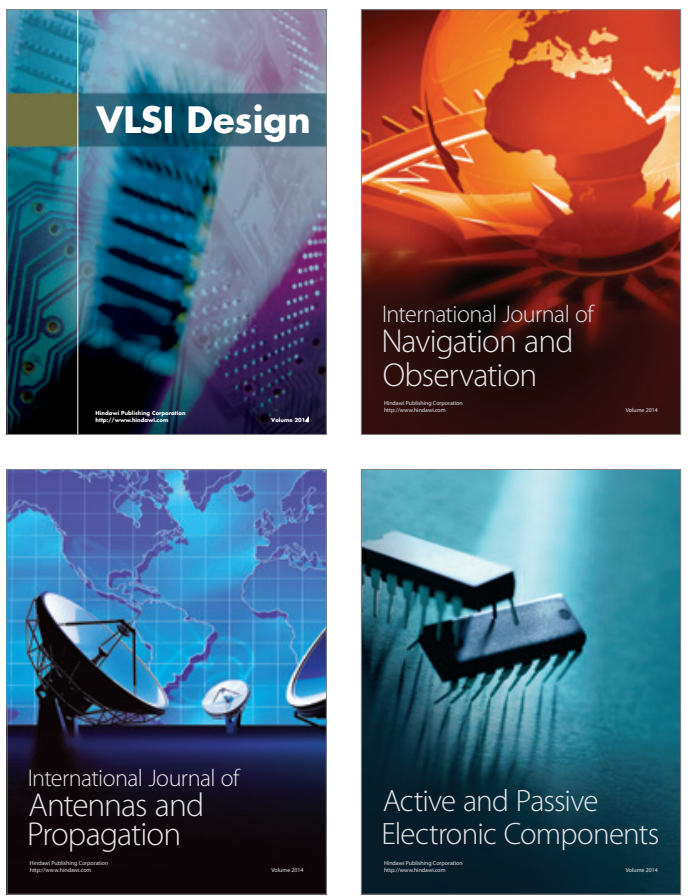
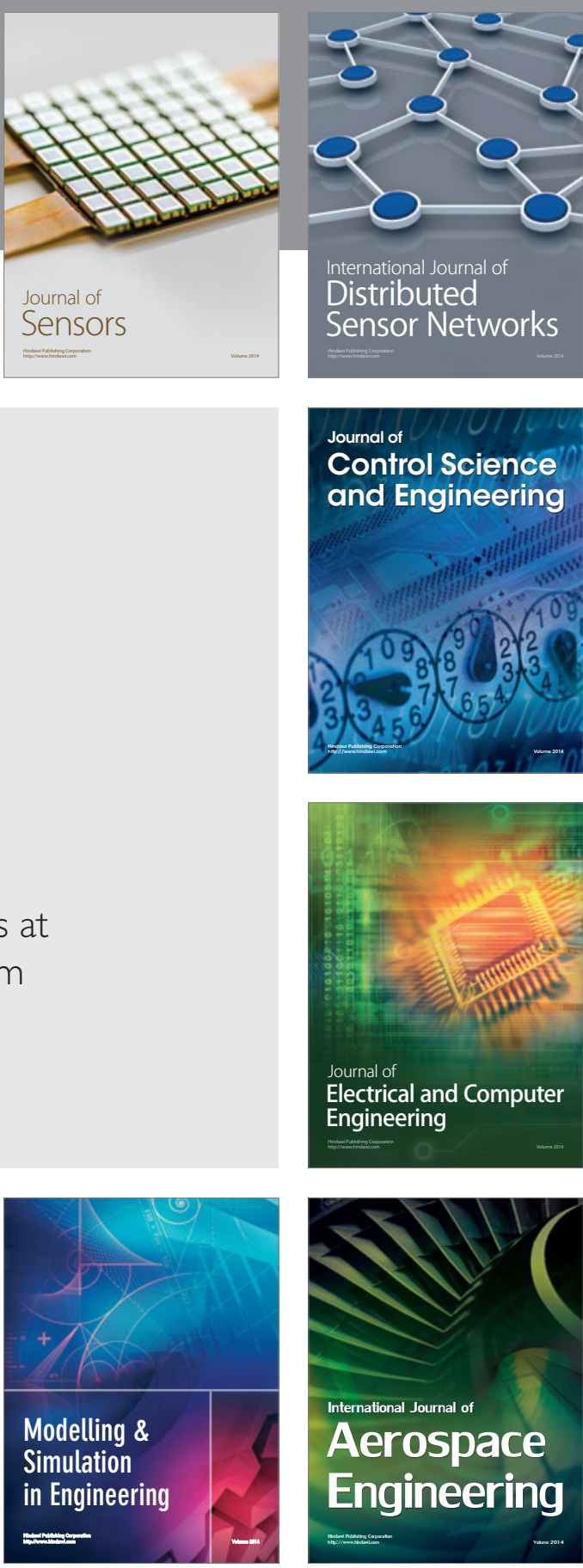

International Journal of

Distributed

Sensor Networks

Journal of

Control Science

and Engineering
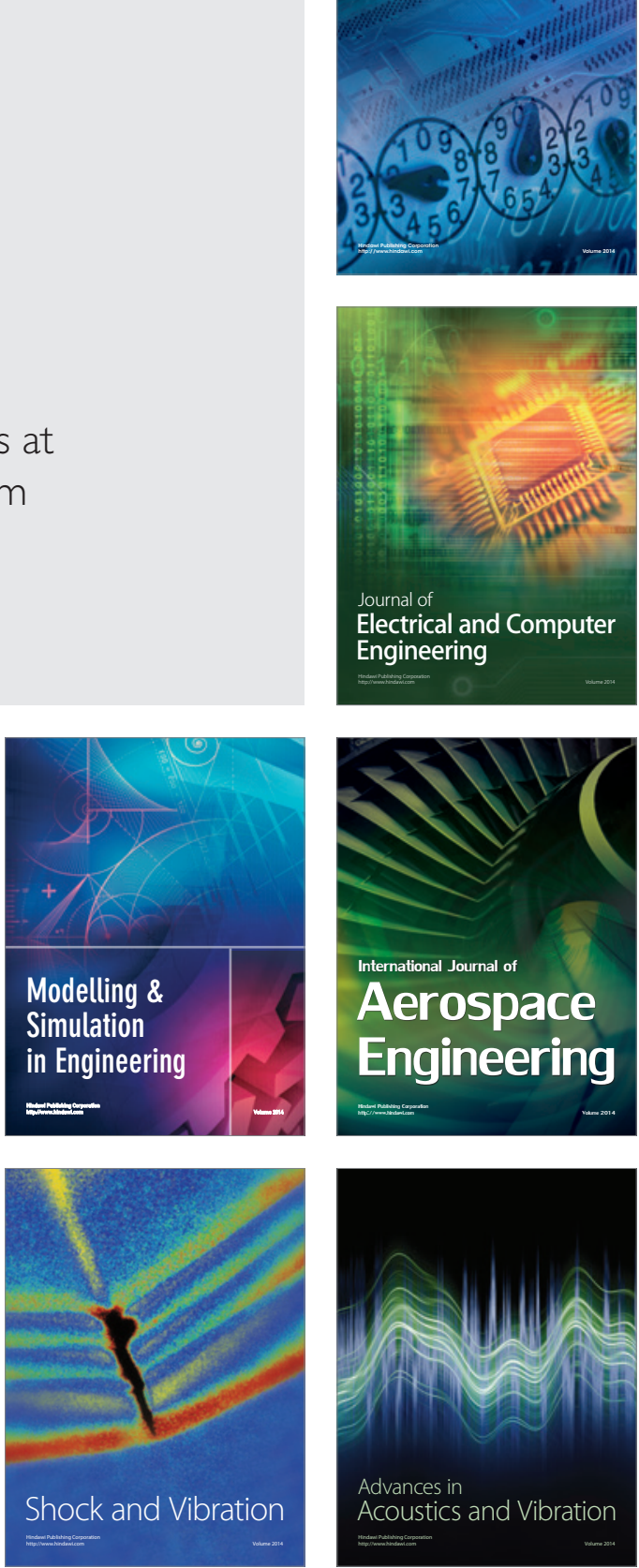